\title{
ANALYSIS OF DIAGNOSTIC VALUE OF CYTOLOGICAL SMEAR METHOD VERSUS CELL BLOCK METHOD IN BODY FLUID CYTOLOGY: STUDY OF 150 CASES
}

\author{
Bhanvadia Viral M. ${ }^{1}$, Santwani P.M. ${ }^{1}$, Vachhani J.H. ${ }^{2}$
}

\begin{abstract}
BACKGROUND: Aspiration of serous cavities is a simple and relatively non-invasive technique to achieve diagnosis. Cytologic evaluation of body cavity fluid is diagnostically challenging.

METHODS: A total of 150 fluid specimens were examined for conventional cytological smear (CS) and cell block method (CB). Out of 150 fluids, 79 were pleural fluid, 69 were ascitic fluid and 2 pericardial fluid. Each fluid specimen was divided in two equal parts: one part was subjected to conventional smear technique, while the other part was subjected to $10 \%$ alcohol-acetic acid-formalin cell block technique. Overall morphological details, cellularity, architecture, nuclear and cytoplasmic details were studied in both CS and CB techniques.

RESULTS: In this study, the utility of the CB method in the cytodiagnosis of malignant effusions was found to be highly significant as compared to the CS method. The additional yield of malignancy was $10 \%$ more as was obtained by the CB method.

CONCLUSION: For the final cytodiagnosis of body fluid, there is statistically significant difference between the two techniques. In other words, CB is superior to CS method.

KEYWORDS: Cell block, Cytodiagnosis, Effusion

DOI: http://dx.doi.org/10.4314/ejhs.v24i2.4
\end{abstract}

\section{INTRODUCTION}

Cytological study of body fluid is a complete diagnostic modality. The information provided by body fluid analysis serves several functions. First, it assists the clinician in formulating and pointing out the etiology of effusion and list of differential diagnoses. Second, it allows one to follow the results of therapy and prognosis.

The accurate identification of cells as either malignant or reactive mesothelial cells is a diagnostic problem in conventional cytological smears. Distinguishing benign from malignant cellular changes may require meticulous screening, careful scrutiny of cellular features and an understanding of the range of reactive changes. Due to cellular overlapping, delaying artifact, suboptimal processing, preparatory cytotechnique and leaving behind useful material causes lower diagnostic yield in CS method. This residual material can be very useful in increasing diagnostic yield by the cell block method. The cell block (CB) technique is one of the oldest and complementary methods for the evaluation of body cavity fluids (1). Cell block preparation increases the sensitivity of detecting malignancies, and also has the ability to reduce false-positive interpretations. A new method of cell block preparation by using $10 \%$ alcohol-acetic acidformalin a fixative was used to identify the sensitivity of the diagnosis in comparison with the conventional smear (CS) study. This method is so simple and inexpensive which requires no extra

\footnotetext{
1Department of Pathology, M.P. Shah Govt. Medical College, Jamnagar, Gujarat, India

${ }^{2}$ Department of Immunohematology \& Blood Transfusion, M.P. Shah Govt. Medical College, Gujarat, India

Corresponding Author: Viral M.Bhanvadia, Email: drviral2001@gmail.com
} 
material compared to other methods. The main advantages of the $\mathrm{CB}$ technique are preservation of tissue architecture and obtaining multiple sections for special stains and immunohistochemistry (2).

In this study, we have assessed and compared the utility of cell block and conventional smear technique in the cytodiagnosis of malignant effusion.

\section{METHODS}

The present study was conducted on 150 patients who underwent paracentesis for the diagnosis of effusion cytology (pleural+ascitic+pericardial fluid) by CS \& CB method. A total 150 fluid specimen (pleural+ascitic+pericardial fluid) were received in the Cytopathology section, Department of Pathology, M. P. Shah Govt. Medical College, Jamnagar, Gujarat, India from June 2010 to June 2012. All the 150 fluid specimens were included in the study. Written informed consent of all the patients in the study was obtained. Clotted fluid specimen, time between collection and processing more than one hour and suboptimal preserved fluid specimens were excluded from our study. Thereafter, cytological diagnosis was made.

Ten milliliters of each fresh fluid specimen was divided into two equal parts of five milliliters each. One part was subjected to the conventional smear cytology technique and the other part for the cell block technique.

In conventional smear technique, the 5 milliliter fluid specimens were centrifuged at 2500 rpm for 10 minutes. A minimum of 3 smears were prepared from the sediment. One smear was prepared after air drying and it was stained with the May-Grünwald-Giemsa stain. The other two smears were immediately fixed in 95\% alcohol, and were stained with the Papanicolaou stain and Haematoxylin-Eosin stain.

In cell block technique, we used AAF fixative (95\% ethyl alcohol $34 \mathrm{ml}+$ Glacial acetic acid 2 $\mathrm{ml}+$ formalin $4 \mathrm{ml}$ ). After centrifugation at 2500 rpm for 10 minutes, cell sediment was formed. Cell sediment was mixed with thrice the volume of AAF fixative, and one or two drops of the mixture fluid was centrifuged for 10 minutes at $2000 \mathrm{rpm}$. Again, re-suspended the cell button in AAF fixative and centrifuged for 10 minutes at $3000 \mathrm{rpm}$. The centrifuged tube was set aside undisturbed for 4 - 6 hours. The cell button was scraped out and wrapped in filter paper and processed in automatic tissue processor for routine histopathology section. The cell blocks were embedded in paraffin and sectioned at $4 \mu \mathrm{m}$ thickness Thus, the same fluid specimen was evaluated for a comparative purpose. Special stain, Diastase-Periodic acid Schiff (D-PAS), Mucicarmine and Alcian blue were done whenever needed.

Morphological criteria including cellularity, arrangement of cells, nuclear and cytoplasmic details were put together and used for the categorization of the fluid specimens. Patients were diagnosed through clinical history, laboratory tests, radiological examination, cytological examination, cell block technique, and subsequently, each was categorized by Benign, suspicious for malignancy and Malignant effusion. Data was entered into Microsoft excel 2007 sheet and analyzed. Proportion and chi-square test statistic were calculated. To find out the whether the results were statistically significant or not, $\mathrm{x}^{2}$ was used. Critical level of significance was fixed at $95 \%$ level. Here, $X^{2}=5.96$ and $p=0.01$ [Upper two row clubbed to avoid Yates correction in Table-3]. Assessment and comparative evaluation of the $\mathrm{CS}$ versus the $\mathrm{CB}$ techniques were carried out.

\section{RESULTS}

All the 150 fluid specimens were subjected to the $\mathrm{CS}$ and the CB techniques. It was then observed that out of total 150 specimens studied, 79(53\%) were of pleural fluid, 69(46\%) were of ascitic fluid and $2(1 \%)$ specimens were of pericardial fluid, both of them were in male patients between the age group of 50-59 years. (Table 1).

It was seen that $61(66 \%)$ of male and 18 (31\%) of female patients had pleural effusion; 29 $(32 \%)$ of male and $40(69 \%)$ of females had ascitic fluid. Amongst the total number of specimen studied, Males predominantly had pleural effusion and females had ascitic effusion. Two specimens of pericardial fluid were received and both were from male patients (Table 1).

Maximum numbers of cases were recorded in the $4^{\text {th }}$ and $5^{\text {th }}$ decades in both pleural and ascitic effusion. 
Of the 150 fluids studied, 91 were Transudative effusions. Smears from such fluids showed only scarce cellularity comprising of scattered inflammatory cells and few benign mesothelial cells. Causes such as cirrhosis, congestive cardiac failure, nephrotic syndrome, hypoprotenemia were observed as per clinical history. Out of 91 Transudative effusion, 48(53\%) cases belonged to pleural effusion, $41(45 \%)$ belongs to ascitic effusion and 2(2\%) were from pericardial effusion (Table 1).
Of the total 150 fluid specimens, 59 were Exudative effusions. It shows predominantly neutrophil, lymphocyte, macrophage, few RBCs occasional necrotic material and mesothelial cells showed range of reactive changes. Gaps and windows were also seen between adjacent reactive cells. Causes were acute infection, tuberculosis, malignancy, trauma, rheumatoid arthritis and subphrenic abcess. Out of 59 Exudative effusion, $31(53 \%)$ cases belonged to pleural effusion while $28(47 \%)$ belonged to ascitic effusion (Table 1$)$.

Table 1: Distribution of number of fluid specimen among gender \& type by conventional smear based diagnosis

\begin{tabular}{l|lllll}
\hline & Sample & Male & Female & Transudate & Exudate \\
\hline Pleural Fluid & $79(53 \%)$ & $61(66 \%)$ & $18(31 \%)$ & $48(53 \%)$ & $31(53 \%)$ \\
Ascitic Fluid & $69(46 \%)$ & $29(32 \%)$ & $40(69 \%)$ & $41(45 \%)$ & $28(47 \%)$ \\
\hline Pericardial Fluid & $02(1 \%)$ & $02(2 \%)$ & $00(0 \%)$ & $02(2 \%)$ & $00(0 \%)$ \\
Total & $150(100 \%)$ & $92(61 \%)$ & $58(39 \%)$ & $91(61 \%)$ & $59(39 \%)$ \\
\hline
\end{tabular}

One hundred and sixteen fluid specimens were categorized as benign effusion by CS method; $61(53 \%)$ specimens belonged to pleural effusion; $53(46 \%)$ specimens belonged to ascitic fluid, $2(1 \%)$ were from pericardial effusion, $18(12 \%)$ fluid specimens were categorized as malignant effusion by CS method, $10(56 \%)$ specimens belonged to Pleural effusion and 08(44\%) specimens belonged to ascitic effusion. Sixteen fluid specimens were categorized as suspicious of malignant effusion by CS method; $8(50 \%)$ specimens belonged to pleural effusion and $8(50 \%)$ specimens belonged to ascitic effusion (Table 2).

Table 2: Distribution of number of fluid specimen among Benign, Suspicious of malignant \& Malignant effusion by conventional smear (CS) based diagnosis

\begin{tabular}{l|llll}
\hline & Sample & Benign & Suspicious & Malignant \\
\hline Pleural Fluid & $79(53 \%)$ & $61(53 \%)$ & $08(50 \%)$ & $10(56 \%)$ \\
Ascitic Fluid & $69(46 \%)$ & $53(46 \%)$ & $08(50 \%)$ & $08(44 \%)$ \\
\hline Pericardial Fluid & $02(1 \%)$ & $02(1 \%)$ & $00(0 \%)$ & $00(0 \%)$ \\
Total & $150(100 \%)$ & $116(77 \%)$ & $16(11 \%)$ & $18(12 \%)$ \\
\hline
\end{tabular}

By the CB method, additional 15 cases were detected as malignant, that is a $10 \%$ more diagnostic yield for malignancy. Besides, 01 specimen was diagnosed as benign effusion by $\mathrm{CB}$ method (Table 3). These 16 fluid specimens were reported as suspicious for malignancy by CS method previously. Thus cellular yield which was obtained by the CB method was more when it was compared to the one which was obtained by the CS method. After CB method was applied, diagnostic sensitivity and specificity increased.
Table 3: Analysis of CS and $\mathrm{CB}$ methods in total 150 fluid samples $\left(X^{2}=5.96, p=0.01\right.$, upper two row clubbed to avoid Yates correction)

\begin{tabular}{|l|l|l|l|}
\hline No. & $\begin{array}{l}\text { Diagnostic } \\
\text { category }\end{array}$ & $\begin{array}{l}\text { CS Method } \\
\text { (Total) }\end{array}$ & $\begin{array}{l}\text { CB Method } \\
\text { (Total) }\end{array}$ \\
\hline 1 & Benign & $116(77 \%)$ & $117(78 \%)$ \\
\hline 2 & $\begin{array}{l}\text { Suspicious for } \\
\text { malignancy }\end{array}$ & $16(11 \%)$ & $00(0 \%)$ \\
\hline 3 & Malignant & $18(12 \%)$ & $33(22 \%)$ \\
\hline & Total & $150(100 \%)$ & $150(100 \%)$ \\
\hline
\end{tabular}

Finally, after CB method, of a total of 33 cases of malignant effusions, 16 belonged to pleural effusion and 17 to ascitic effusion. Out of 16 
malignant pleural fluid effusions, 8 were due to adenocarcinoma lung, 5 were due to squamous cell carcinoma of lung, 2 were due to breast carcinoma and 1 was due to mesothelioma. Amongst 17 malignant ascitic cases, 09 were secondary ones from ovary, 5 were due to colonic malignancy (Fig 1), 2 were from liver carcinoma whilst 1 was from pancreatic carcinoma. Cases were correlated clinically, radiologically and confirmed by histopathological examination whenever possible.

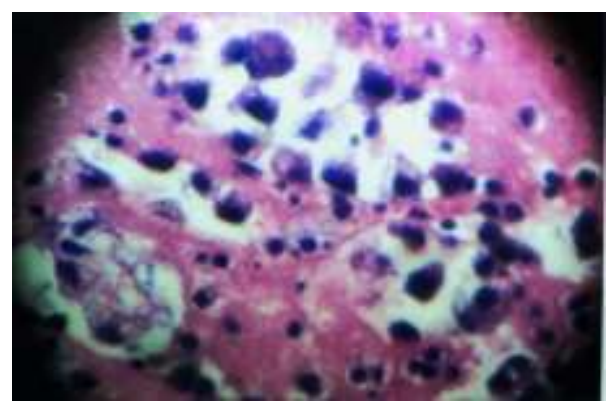

Figure 1: (Hematoxylin \& Eosin stain,400x), Cell block preparation shows malignant glandular epithelial cells arranged in glandular pattern of adenocarcinoma

The statistical analysis of the 150 fluid specimens showed a higher cellular yield by the CB method than by the CS method. Therefore, in this study, the utility of the CB method in the cytodiagnosis of malignant effusions was found to be highly significant as compared to the CS method.

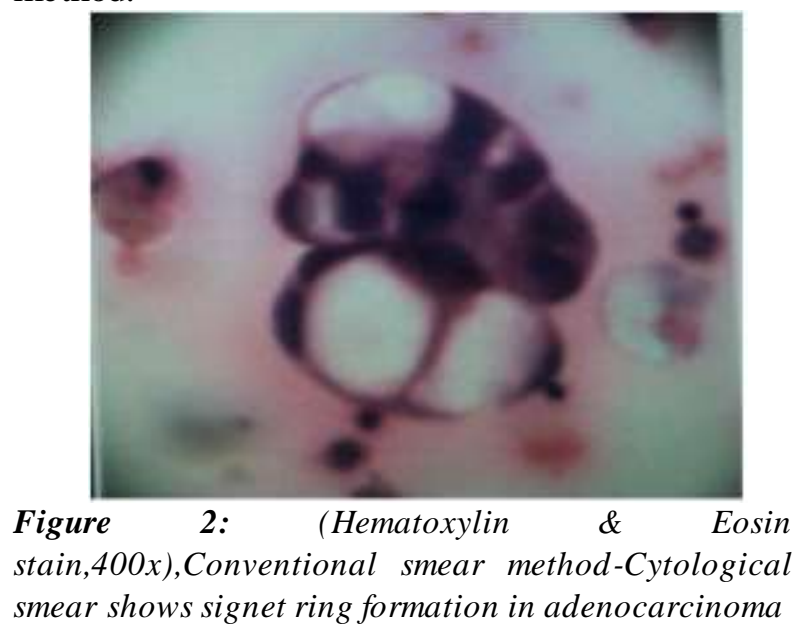

\section{DISCUSSION}

The cell population in sediment of body fluid represents a much larger surface area than obtained by needle biopsy. Since the introduction of the $\mathrm{CB}$ technique by Bahrenburg nearly a century ago, it has been used routinely for processing fluids (2). Cell blocks prepared from residual tissue fluid can be used as adjuncts to smear for establishing a more definitive cytopathological diagnosis. The technique is simple, safe, cost-effective and reproducible even in resource limited settings (3). Cell blocks provided the best milieu for morphologic interpretation, with less background staining and results that most closely approximated those reported in the surgical pathology literature (4).

The malignant cells in the pleural or the ascitic fluids were almost always indicative of metastatic tumours, as primary malignancies which arose from the mesothelial cell lining were uncommon. A positive effusion for malignant cells is an important prognostic indicator in cancer patients (5). The development of a malignant pleural effusion is a common complication and indication of advanced stages of cancers like lung, breast and stomach cancer, while development of malignant ascitic effusion is due to ovary, colon, liver and pancreatic carcinoma. Thus, the examination of body fluids for the presence of malignant cells has been accepted as a routine laboratory procedure for detection of metastasis of unknown primary origin $(6,7)$.

Of the total 150 specimens studied, 79(53\%) were of pleural fluid; $69(46 \%)$ were of ascitic fluid and 2(1\%) specimens were of pericardial fluid. Sixty-one (66\%) male and forty (69\%) female cases were highest in number in pleural and ascitic fluid effusion category respectively. In the age group of $4^{\text {th }}$ and $5^{\text {th }}$ decades, out of the 150 fluids, 91 were transudative, and 59 were exudative effusions (Table 1).

Out of a total of 150 specimens, $116(77 \%)$ belonged to benign; 16(11\%) belonged to suspicious of malignancy and $18(12 \%)$ were malignant effusion category by CS method. But, 116 benign fluid specimens comprise of $61(53 \%)$ of pleural effusion, 53(46\%) of ascitic 
effusion and 2(1\%) of pericardial effusion. Our study is in agreement with the study of Luse et al on the effusion (8).

Out of 34 fluid specimens, malignancy proven by FNAC/Histopathology, 18(53\%) cases were positive for malignant cells by CS alone. Our study is comparable with the study by Chandler who showed 65\% accuracy and with Ceelen who proved $71 \%$ accuracy in the result by smear method of effusion $(9,10)$.

Out of the 34 fluid specimens, malignancy proven by FNAC/Histopathology, 33(97\%) cases were positive for malignant cells by $\mathrm{CB}$ method. Thus finding of the present study is consistent with all other previous study, like Thapar et al $86 \%$, Ceelen $89 \%$ and Zemansky AP $90 \%$ accuracy by cell block method $(6,10,11)$.

After the study with CB method, 16 specimens of suspicious for malignancy turned to 15 specimens of malignant category and 01 specimens of benign effusion (Table-3). Thus, by using $\mathrm{CB}$ method, $10 \%$ additional diagnostic yield can be obtained, which is in line with the study done by Thapar $\mathrm{M}$ et al showed 13\%, Richardson et al showed $12 \%$ and Liu et al showed $12 \%$ increase in diagnosis $(6,12,16)$.

In the CS method, there are plenty of reactive mesothelial cells, inflammatory cells and a paucity of representative cells; lack of tissue architecture contribute to the considerable difficulties which are faced while making conclusive diagnosis (5). Reactive mesothelial cells show multinucleation, high nuclear: cytoplasmic ratio and mitotic figure are great mimicker of malignant cells even to the experienced observer. It can be seen in traumatic irritation of serosa, chronic inflammation, infarction, post-radiotherapy and postchemotherapy. CS has a sensitivity of only 40 $70 \%$ for detecting the presence of malignant diseases, due to the overcrowding of the cells, and processing artifacts.

The CB method, the method uses histological techniques for processing and thus offers a major advantage. Multiple sections of the same material may be processed for routine stains and for special stains that may serve for immunhistochemistry and for identification of mucin, melanin or other cell products and identification of bacteria and fungi. $\mathrm{CB}$ technique is simple, safe and reproducible. The $\mathrm{CB}$ technique should be used for processing all residual material after completion of cytological preparations. The material often contains valuable diagnostic evidence and tissue fragments that cannot be processed by cytological technique. Malignant cells not present on the smears often are found within the cell block. Cases that are suspicious or equivocal on the smears can be diagnosed definitively with the aid of a cell block preparation (15).

There is a statistically significant difference between the two techniques. In other words, $\mathrm{CB}$ method is superior to CS in final cytodiagnosis (Table 3). The additional benefit of cell block technique is the recognition of histologic patterns of disease that sometimes cannot be reliably identified in smears preparations. The glandular structures, papillary structure and demonstration of mucin in cytoplasm of tumour cells forming signet ring can be more reliably seen in cell block method for the diagnosis of adenocarcinoma. It is particularly helpful to differentiate between mesothelioma and metastasis of adenocarcinoma in fluid (Fig 2).

Cell blocks made from cell or tissue remnants can also be used for immunohistochemistry of specific biomarkers for accurate diagnosis of malignancy (17). Some Immunohistochemistry markers like calretinin, WT-1, $\mathrm{CK}_{5 / 6}$ and D2-40 are positive for mesothelioma in contrast to adenocarcinoma. The contribution of cell blocks to the final cytologic diagnosis supports the view that cell blocks should be considered in cases of exfoliative cytology specimens after review of the smears (18).

There are many methods for cell block preparation like Plasma thrombin clot method, bacterial agar method, compact block technique, cell block from milipore filter method. The routine use of cell block by these methods is not costeffective, since it requires additional materials and extra time as compared to the $10 \%$ AAF method.

The current CB technique, which uses $10 \%$ alcohol-acetic acid-formalin as a fixative, was found to be simple and inexpensive-it does not require special training or special instruments. The principle of this technique is that formalin causes the proteins to be cross linked and a gel would be formed, which could not be dissolved in any material during processing of fluid specimens, thus minimizing the cell loss. The advantage of 
alcohol based fixative is better preservation of antigenicity and cytomorphological features.

In the present study, most of the malignant neoplasm in ascitic fluids was derived from adenocarcinoma of ovarian tumours, which is in accordance with the study of Monte SA et al., while those of pleural effusions come mainly from adenocarcinoma of lung (19). Gaur DS et al's study showed that adenocarcinoma of lung was the most frequent type of malignancy found in pleural effusions (20). By using a combination of the CS and the CB methods along with clinical, radiological and the cytological features, the primary site could be determined with $90 \%$ accuracy (21). In developing countries like India, due to shortage of health and laboratory investigation facilities, it is investigation of choice that helps in diagnosing cases before discarding specimens that are negative for malignant cells by smear examination.

To conclude, the additional yield for the malignancy was found to be $10 \%$ more by $\mathrm{CB}$ as compared to that obtained by CS method. Therefore, we can reduce false negative results and increase diagnostic sensitivity and specificity. CB technique which uses $10 \%$ alcohol-acetic acid-formalin as a fixative is simple, safe, inexpensive and reproducible. A combined use of smears and cell block is recommended to raise further diagnostic accuracy.

\section{REFERENCES}

1. Kushwaha R, Shashikala P, Hiremath S, Basavaraj HG. The cells in the pleural fluid and their value in the differential diagnosis. J Cytol, 2008;25:138-43.

2. Shivakumarswamy U, Arakeri SU, Mahesh H Karigowdar MH, Yelikar BR. Diagnostic utility of the cell block method versus the conventional smear study in pleural fluid cytology. J Cytol, 2012;29:11-15.

3. Ghosh I, Dey SK, Das A, Bhattacharjee D, Gangopadhyay S, Cell block cytology in pleural effusion. Journal of the Indian Medical Association, 2012, 110(6):390-2, 396.

4. Fetsch PA, Simsir A, Brosky K, Abati A: Comparison of three commonly used cytologic preparations in effusion immunocytochemistry. Diagn Cytopathol, 2002;26:61-66.

5. Shivakumarswamy U, Arakeri SU, Mahesh $\mathrm{H}$ Karigowdar MH, Yelikar BR. The role of the cell block method in the diagnosis of malignant ascitic fluid effusions. Journal of Clinical and Diagnostic Research 2012;6:1280-3.

6. Thapar M, Mishra RK, Sharma A, Goyal V. A critical analysis of the cell block versus smear examination in effusions. J Cytol, 2009;26:60.

7. Wong JW, Pitlik D, Abdul-Karim FW. Cytology of pleural, peritoneal and pericardial fluids in children- A 40 years summary. Acta Cytol, 1997;41:467-73.

8. Luse SA, Reagan JW. A histocytologic study of effusions: II, Effusions associated with malignant tumors. Cancer, 1954;7:1167-81.

9. Foot NC. The identification of neoplastic cells in serous effusions. Am J Pathol, 1939;27:53-60.

10. Guenther H. Ceelen: The cytologic diagnosis of ascitic fluid. Acta Cytol, 1964:8:175-85.

11. Zemansky AP Jr. The examination of fluids for tumor cells: An analysis of 113 cases checked against subsequent examination of tissue. Am J M Sci, 1928;175:489-504.

12. Richardson HL, Koss LG, Simon TR. Evaluation of concomitant use of cytological and histological technique in recognition of cancer in exfoliated material from various sources. Cancer, 1955;8:948-50.

13. Mezger J, Stotzer O, Schilli G, Bauer S, Wilmanns W. Identification of carcinoma cells in ascitic and pleural fluids. Comparis on of four panepithelial antigens with the carcinoembryonic antigen. Acta Cytol, 1992;36:75-81.

14. Price BA, Ehya H, Lee JH. The significance of the pericellular lacunae in the cell blocks of effusions. Acta Cytol, 1992;36:333-37.

15. Keyhani-Rofagha S, Vesey-Shecket M. Diagnostic value, feasibility, and validity of preparing cell blocks from fluid-based gynecologic cytology specimens. Cancer Cytopathol, 2002; 96:204 209.

16. Liu K,Dodge K,Glassgow BJ et al, comparis on of smears, cytospin \& cell block preparation in diagnostic \& cost effectiveness. Diagn cytopathol, $1998 ; 19(1): 70-4$.

17. H. Sakamoto, M. Takenaka, K. Ushimaru and T. Tanaka. Use of Liquid-Based Cytology (LBC) and Cell Blocks from Cell Remnants for Cytologic, Immunohistochemical, and Immunocytochemical Diagnosis of Malignancy. Open Journal of Pathology, 2012; 2: 58-65.

18. Nathan NA, Narayan E, Smith MM, Horn MJ. Cell block cytology. Improved preparation and its efficacy in diagnostic cytology. Am J Clin Pathol, 2000;114:599-606.

19. Monte SA,Ehya $\mathrm{H}$ et al. Positive effusion cytology as the initial presentation of malignancy. Acta cytol 1987;31(4):448-52. 
20. Gaur DS, Chauhan N, Kusum A et al. Pleural fluid analysis-role in diagnosing pleural malignancy. $J$ cytol, 2007;24:183-88.

21. Khan N, Sherwani RK, Afroz N, Kapoor S. The cytodiagnosis of malignant effusions and determination of the primary site. J cytol, 2005; 22: 107-10. 